\title{
A STUDY COMPARING THREE DIFFERENT CHEMO-RADIATION TECHNIQUES IN MANAGEMENT OF CERVICAL CANCER
}

\author{
Suman Ghorai1, Bikramjit Chakrabarti ${ }^{2}$
}

1Associate Professor, Department of Radiotherapy, Bankura Sammilani Medical College and Hospital, Bankura, West Bengal, India. ${ }^{2}$ Assistant Professor, Department of Radiotherapy, IPGME\&R and SSKM Hospital, Kolkata, West Bengal, India.

\begin{abstract}
BACKGROUND

In developing countries, majority of cervical cancer patients present in locally advanced stage, where concomitant chemoradiation is the treatment of choice. Despite treatment, 5-year recurrence free survival is about only $79 \%$ for stage IB, IIA disease and $59 \%$ for III/IVA disease with about $36.7 \%$ failing locally within central pelvis. However, due to huge number of patients and lower number of available radiation installations, there is sometimes a delay in commencement of radiation. Therefore, many oncolog ists often use neo-adjuvant chemotherapy before external radiation, while others practice hypo-fractionated radiotherapy. However, there is no published data comparing treatment by neoadjuvant chemotherapy or hypofractionation with standard concomitant chemo-radiation.
\end{abstract}

\section{METHODS}

Histologically proven squamous cell carcinoma cervix of stage IB2, IIA2-IIB-IVA were included in our study. Patients were randomized to receive either concomitant chemoradiation with a radiation dose of 50 Gy in conventional fractionation and concomitant weekly injection cisplatin $40 \mathrm{mg} / \mathrm{m}^{2}$ as radio-sensitizer, followed by brachytherapy; or two cycles of neoadjuvant chemotherapy with carboplatin AUC 6 along with injection paclitaxel $175 \mathrm{mg} / \mathrm{m}^{2}$ followed by hypo-fractionated external beam radiation (42 Gy in 16 fractions over 3.5 weeks) started within 3 weeks of chemotherapy; or three cycles of neoadjuvant chemotherapy with same regimen followed by concomitant chemoradiation. Disease free survival at two years and toxicities of treatment (by Common Terminology Criteria for Adverse Events version 5.0) were statistically compared by one-way ANOVA using IBM SPSS Statistics ${ }^{\circledR}$ software version 20.

\section{RESULTS}

Patient characteristics were similar in all arms. Complete response was slightly higher after concomitant chemoradiation. Disease free survival and rectal toxicity were slightly higher following hypo-fractionated radiotherapy. These differences were statistically insignificant. Late toxicity encountered, were limited to grade I-II nephrotoxicity and rectal toxicity. All three modalities of treatment provided comparable outcome in terms of efficacy and toxicities when observed for a two year follow up period.

\section{CONCLUSIONS}

For cancer treatment centers overburdened with patients, treatment by hypo-fractionation is a suitable alternative and is statistically non-inferior to the standard practice of concomitant chemoradiation. Studies with larger patient population and longer follow up period need to be conducted to validate inferences.

\section{KEY WORDS}

Cervical, Cancer, Radiation, Fractionation

HOW TO CITE THIS ARTICLE: Ghorai S, Chakrabarti B. A study comparing three different chemo-radiation techniques in management of cervical cancer. J. Evolution Med. Dent. Sci. 2019;8(24):1900-1903, DOI: 10.14260/jemds/2019/418

\section{BACKGROUND}

Cervical cancer is the fourth most common cancer in women worldwide.[1,2] In the United States and other developed countries, age adjusted death rates from cervical cancer have declined steadily since the 1930 s. This decrease is primarily the result of the adoption of routine screening programs, although the death rates from cervical cancer had begun to decrease before the implementation of Papanicolaou (Pap)

'Financial or Other Competing Interest': None.

Submission 16-04-2019, Peer Review 04-06-2019,

Acceptance 10-06-2019, Published 17-06-2019.

Corresponding Author:

Bikramjit Chakrabarti,

Room 2, Department of Radiotherapy,

IPGME\&R and SSKM Hospital,

244 AJC Bose Road, Kolkata-700020,

West Bengal, India.

E-mail:jtbkm@yahoo.com

DOI: $10.14260 /$ jemds $/ 2019 / 418$

\section{(c) $(\mathrm{P})($}

screening, suggesting that other unknown factors may have played some role.[3] A large majority (Around $85 \%$ ) of the global burden occurs in less developed countries, where it accounts for almost $12 \%$ of all female cancers. Almost nine out of ten $(87 \%)$ cervical cancer deaths occur in the less developed regions.[4] International incidences of cervical cancer tend to reflect differences in cultural attitudes toward sexual practices and difference in the penetration of mass screening programs, with highest incidences occurring in populations that have a high background prevalence of human papilloma virus (HPV) infection combined with low screening rates.

Except for very early cases, radiation therapy is the major curative treatment option[5] and brachytherapy plays an anchor role in management of locally advanced disease.[6] Although outcomes are poorer for patients with larger tumours, even these are frequently curable with a combination of external beam irradiation and brachytherapy. However, patients with stage $\mathrm{IB}_{2}$ and bulky stage IIA cancers are usually treated with concurrent cisplatin based 
chemoradiation, which has been demonstrated in randomized trials to yield better outcomes than radiotherapy alone.

In developing countries, majority present in locally advanced stage, where concomitant chemoradiation is the treatment of choice. Despite, concomitant chemo-radiation, 5 year recurrence free survival is about only $79 \%$ for stage IB, IIA disease and 59\% for III/IVA disease with about $36.7 \%$ failing locally within central pelvis despite this aggressive course of chemoradiation.[7] Apart from point A cumulative dose (mean $\mathrm{EQD}_{2}$ ), stage, histology and treatment gap were the factors that affected early local failure after treatment. An interesting result was that follow-up pattern has a significant impact on disease free survival period.[8] The NRG/GOG combined data[9] from randomized trials of chemoradiotherapy and created nomograms predicting progression free survival, overall survival and pelvic recurrence in locally advanced cervical cancer. Multivariate analysis identified histology, race and/or ethnicity, patient's performance status, tumour size, stage, grade, pelvic node status and treatment with cisplatin based concurrent chemotherapy as significant measures for outcomes.

However, due to huge number of patients and lower number of available radiation installations, there is sometimes a delay in commencement of radiation for these patients. Therefore, many oncologists often use neo-adjuvant chemotherapy before starting external radiation, while others practice hypo-fractionated radiotherapy. However, there is no published data comparing treatment by neoadjuvant chemotherapy or hypofractionation with standard concomitant chemoradiation. In our study, we compared clinical outcomes of locally advanced carcinoma cervix patients after treatment with radical chemoradiation with that after treatment with neoadjuvant chemotherapy followed by hypo-fractionated radiotherapy and brachytherapy and that after treatment with neoadjuvant chemotherapy followed by concomitant chemoradiation.

\section{METHODS}

Patients suffering from histologically proven squamous cell carcinoma cervix of stage $\mathrm{IB}_{2}$, IIA 2 -IIB-IVA with good performance status and normal routine investigations and renal and liver function tests, and registered during February to September 2016 were included in our study. Patients not meeting above inclusion criteria were excluded from our study. In this hospital-based study, all patients diagnosed with cervical cancer were intended to be included and sample size calculation by Cochran's formula was not needed. A total of 156 patients were included in our study.

After IEC clearance and informed consent in patient's own language, patients were randomized by blind envelope method to receive either concomitant chemoradiation with a radiation dose of $50 \mathrm{~Gy}$ in conventional fractionation and concomitant weekly injection cisplatin $40 \mathrm{mg} / \mathrm{m}^{2}$ as radiosensitizer, followed by brachytherapy or two cycles of neoadjuvant chemotherapy with carboplatin AUC 6 along with injection paclitaxel $175 \mathrm{mg} / \mathrm{m}^{2}$ followed by hypofractionated external beam radiation ( 42 Gy in 16 fractions over 3.5 weeks) started within 3 weeks of chemotherapy or three cycles of neoadjuvant chemotherapy with same regimen followed by concomitant chemoradiation. During external beam irradiation, all patients were treated by four field box technique. Brachytherapy was performed with a dose of 85-90 Gy EQD2 delivered to target volume by threedimensional computerized treatment planning. Clinical assessment, blood, stool and urine examination along with imaging and endoscopy, when required, was done periodically during follow up. Disease free survival at the end of two years and toxicities of treatment by Common Terminology Criteria for Adverse Events (CTCAE) version 5.0 were recorded for all cases.

\section{Statistical Methods}

The arms were compared by one-way ANOVA using IBM SPSS Statistics ${ }^{\circledR}$ software version 20 .

\section{RESULTS}

In our study, patient characteristics were similar in all arms (Table 1). Complete response was slightly higher with concomitant chemoradiation arm. But this difference was not statistically significant (Table 2). On the other hand, disease free survival and rectal toxicity were slightly higher in hypofractionated radiotherapy arm (Table 3). This difference also was statistically insignificant. Late toxicity encountered, were limited to grade I-II nephrotoxicity and rectal toxicity. Thus, all three modalities of treatment provided comparable outcome in terms of efficacy and toxicities when observed for a two year follow up period.

\section{DISCUSSION}

Cisplatin has been studied in a variety of doses and schedules in the management of recurrent or metastatic cervical cancer and is considered the most active agent against this malignancy.[10] Although investigators were initially encouraged by high response rates of untreated cervical cancer to multiple agent, cisplatin containing chemotherapy regimens, these results have not translated to a clear advantage when neo-adjuvant chemotherapy is given before radiotherapy. Most prospective randomized trials have demonstrated either no benefit or poorer survival when neoadjuvant chemotherapy was added to radiation therapy.[11]

Altered fractionation radiation therapy is one of the attempts to improve therapeutic ratio in hope of controlling locally advanced tumours by radiation therapy alone.[8] Reduction of total prescribed dose from 50 Gy in conventional fractionation to 45 Gy in 25 fractions even lowers risk of complications like pelvic insufficiency fracture.[12]

MacLeod et al.[13] reported on a phase II trial of 61 patients with locally advanced cervical cancer treated with accelerated hyper fractionated radiation therapy (1.25 Gy administered twice daily at least 6 hours apart to a total pelvic dose of $57.5 \mathrm{~Gy}$ ). A boost dose was administered with either low-dose rate (LDR) brachytherapy or EBRT to a smaller volume. Thirty patients had acute toxicity that required regular medication. One patient died of acute treatment-related toxicity. The overall 5-year survival was $27 \%$, relapse-free survival was $36 \%$, and actuarial local tumour control was $66 \%$. There were eight severe late complications observed in seven patients, who required surgical intervention (actuarial rate of 27\%). Five patients also required total hip replacement. 


\begin{tabular}{|c|c|c|c|c|}
\hline & $\begin{array}{c}\text { Concomitant } \\
\text { Chemoradiation } \\
\text { Using } \\
\text { Conventional } \\
\text { Fractionation }\end{array}$ & $\begin{array}{c}\text { Neoadjuvant } \\
\text { Chemotherapy } \\
\text { Followed by } \\
\text { Hypo- } \\
\text { Fractionated } \\
\text { Radiotherapy }\end{array}$ & $\begin{array}{c}\text { Neoadjuvant } \\
\text { Chemotherapy } \\
\text { Followed by } \\
\text { Concomitant } \\
\text { Chemoradiation }\end{array}$ & $\begin{array}{c}\mathbf{p} \\
\text { Value }\end{array}$ \\
\hline $\begin{array}{c}\text { Number } \\
\text { of patients }\end{array}$ & 48 & 53 & 55 & \\
\hline $\begin{array}{c}\text { Median } \\
\text { age }\end{array}$ & 50 years & 54 years & 53 years & 0.99 \\
\hline Stage & & & & \\
\hline IB2 & 3 & 2 & 2 & 0.72 \\
\hline IIA2 & 4 & 3 & 6 & \\
\hline IIB & 12 & 15 & 17 & \\
\hline III & 26 & 29 & 22 & \\
\hline IVA & 3 & 4 & 8 & \\
\hline & Table 1. Patient Characteristics & \\
\hline
\end{tabular}

\begin{tabular}{|c|c|c|c|c|}
\hline & $\begin{array}{c}\text { Concomitant } \\
\text { Chemo- } \\
\text { radiation } \\
\text { Using } \\
\text { Conventional } \\
\text { Fractionation }\end{array}$ & $\begin{array}{c}\text { Neoadjuvant } \\
\text { Chemotherapy } \\
\text { Followed by } \\
\text { Hypo- } \\
\text { fractionated } \\
\text { Radiotherapy }\end{array}$ & $\begin{array}{c}\text { Neoadjuvant } \\
\text { Chemotherapy } \\
\text { Followed by } \\
\text { Concomitant } \\
\text { Chemo- } \\
\text { radiation }\end{array}$ & $\begin{array}{c}\mathbf{p} \\
\text { Value }\end{array}$ \\
\hline CR after EBRT & 38 & 36 & 33 & 0.34 \\
\hline $\begin{array}{c}\text { PR after EBRT } \\
\text { and CR after } \\
\text { brachytherapy }\end{array}$ & 6 & 10 & 12 & \\
\hline $\begin{array}{c}\text { PR after } \\
\text { brachytherapy }\end{array}$ & 4 & 7 & 10 & \\
\hline DFS at 2 years & 42 & 43 & 41 & 0.25 \\
\hline \multicolumn{5}{|c|}{ Table 2. Assessment of Response } \\
\hline
\end{tabular}

\begin{tabular}{|c|c|c|c|c|}
\hline & $\begin{array}{c}\text { Concomitant } \\
\text { Chemo- } \\
\text { radiation } \\
\text { Using } \\
\text { Conventional } \\
\text { Fractionation }\end{array}$ & $\begin{array}{c}\text { Neoadjuvant } \\
\text { Chemo- } \\
\text { therapy } \\
\text { Followed by } \\
\text { Hypo- } \\
\text { Fractionated } \\
\text { Radiotherapy }\end{array}$ & $\begin{array}{c}\text { Neoadjuvant } \\
\text { Chemotherapy } \\
\text { Followed by } \\
\text { Concomitant } \\
\text { Chemo- } \\
\text { radiation }\end{array}$ & p Value \\
\hline $\begin{array}{c}\text { Grade III rectal } \\
\text { toxicity }\end{array}$ & 2 & 4 & 3 & 0.76 \\
\hline $\begin{array}{c}\text { Grade III } \\
\text { urinary } \\
\text { bladder } \\
\text { toxicity }\end{array}$ & 0 & 0 & 1 & 0.397 \\
\hline $\begin{array}{c}\text { Grade III small } \\
\text { bowel toxicity }\end{array}$ & 0 & 0 & 0 & compute \\
\hline $\begin{array}{c}\text { Chemotherapy } \\
\text { induced }\end{array}$ & 1 & 0 & 1 & 0.59 \\
\hline nephrotoxicity & \multicolumn{4}{|c|}{ Table 3. Assessment of Late Toxicities } \\
\hline \multicolumn{5}{|l}{} \\
\hline
\end{tabular}

Another study reported on 30 patients with stage II or III cervical cancer randomized to receive either hyperfractionation (15 Patients) or conventional fractionation (15 Patients).[14] At 5 years, two patients in the hyperfractionation group and eight patients in the conventional treatment group had recurrent tumour $(\mathrm{P}=.04)$. Delayed bowel complications (Grade 2 and 3) occurred in nine women in the hyperfractionation group and two patients in the conventional group $(\mathrm{P}=0.0006)$.

RTOG 88-05 conducted a phase II trial of hyperfractionation (1.2 Gy to the whole pelvis twice daily at 4- to 6-hour intervals, 5 days/week) with brachytherapy in 81 patients with locally advanced carcinoma of the cervix. Total dose to the whole pelvis was 24 to $48 \mathrm{~Gy}$, followed by one or two LDR intracavitary applications to deliver 85 Gy at point A and 65 Gy to the lateral pelvic nodes. Grigsby et al.[15] updated the results and noted that external irradiation was completed in 71 cases (88\%). The 5-year cumulative rate of grade 3 and 4 late effects for patients with stage IB2 or IIB tumours was $7 \%$ and at 8 years was $10 \%$, and with stage III or IVA disease, it was $12 \%$ at 5 years. The absolute survival was $48 \%$ at 8 years, and DFS was 33\%. Comparison with historical control patients treated on other RTOG studies showed equivalent rates of pelvic tumour control, survival, and grade 3 and 4 toxicities at 3, 5, and 8 years, respectively.

Calkins et al.[16] assessed the toxicities of multiple daily fractionated (twice-daily, 1.2-Gy fractions) whole-pelvis radiation plus concurrent chemotherapy for locally advanced carcinoma of the cervix. In the first study (GOG 8801), for 38 patients, hydroxyurea was given orally $(80 \mathrm{mg} / \mathrm{kg}$ to a maximum of $6 \mathrm{~g}$ ) at least 2 hours before irradiation, twice every week. In the second study, for 30 patients, cisplatin and fluorouracil (5-FU) were used concomitantly with RT. Acute toxicity was primarily enteric and appeared to be dose related. The maximum tolerated dose of whole-pelvis radiation that could be delivered in a hyper fractionated setting with concomitant chemotherapy was 57.6 Gy in 48 fractions, followed by brachytherapy.

Thomas et al.[17] conducted a four-arm study in which 234 women with bulky stage IB to IVA cervical cancer were randomized to receive either standard RT (EBRT and brachytherapy to deliver 90 Gy to point A) with or without a 4-day infusion of 5 -FU $\left(1 \mathrm{~g} / \mathrm{m}^{2}\right)$ on days 1 to 5 and 22 to 25 or partially hyper fractionated RT with or without the same chemotherapy regimen. The partially hyper fractionated regimen delivered two fractions, 6 hours apart, on the first 4 days of treatment, coinciding with the infusion of 5-FU. The addition of 5FU did not improve pelvic tumour control (37\% to $75 \%$ at 5 Years) or overall survival. However, this study closed without reaching target patient accrual. A concomitant boost technique was reported by Kavanagh et al. [18] but had an unacceptably high rate (8 of 20 Patients) of late complications.

In a study conducted in India, it was suggested that hypo-fractionated radiotherapy can certainly be considered in a select group of patients where the local disease is extensive and is unsuitable for conventional treatment. Survival in patients treated hypo-fractionated radiotherapy appears comparable to that of standard fractionation and toxicities were mild (Acute gastrointestinal and skin reactions were mainly grade I or grade II).[19] Patients were treated with standard pelvic portals to a total dose of 39 Gy in 13 fractions over 17 days followed by intracavitary brachytherapy. Forty-eight patients completed planned treatment and were considered suitable for analysis of late reactions and survival. The 5-year disease free survival was $59 \%$ and overall survival was $50 \%$ at the mean follow up of 40 months. Twenty-one (44\%) patients developed acute gastrointestinal toxicity of which 5 patients had grade III and one patient had grade IV reaction. Ten patients $(21 \%)$ developed acute genitourinary complications, 13 patients (27\%) had late rectal reactions and 10 patients (20\%) had late bladder complications. Three patients had grade I, five had grade II and five had grade III late rectal toxicity. However, there is no study comparing clinical effects of hypofractionation followed by neo-adjuvant chemotherapy to standard chemoradiation. Our study aims at this comparison. 


\section{CONCLUSIONS}

For cancer treatment centres overburdened with patients, treatment by hypo-fractionation is a suitable alternative and is statistically non-inferior to the standard practice of concomitant chemoradiation. It appears to be convenient and drop-outs are less. However, studies with larger patient population and longer follow up period need to be conducted to validate inferences.

\section{REFERENCES}

[1] Torre LA, Bray F, Siegel RL, et al. Global cancer statistics, 2012. CA Cancer J Clin 2015;65(2):87-108.

[2] Torre LA, Islami F, Siegel RL, et al. Global cancer in women: burden and trends. Cancer Epidemiol Biomarkers Prev 2017;26(4):444-58.

[3] Wingo PA, Tong T, Bolden S. Cancer statistics, 1995. CA Cancer J Clin 1995;45(1):8-30.

[4] Singh M, Ranjan R, Das B, et al. Knowledge, attitude and practice of cervical cancer screening in women visiting a tertiary care hospital of Delhi. Indian J Cancer 2014;51(3):319-23.

[5] Chakrabarti B, Basu-Roy S, Kar SK, et al. Comparison of dose volume parameters evaluated using three forward planning-optimization techniques in cervical cancer brachytherapy involving two applicators. J Contemp Brachytherapy 2017;9(5):431-45.

[6] Chakrabarti B., Pal SK, Sepai HM, et al. Clinical and dosimetric consequences of imperfect applicator insertion in cervical cancer brachytherapy. J Contemp Brachytherapy 2018;10(4):321-36.

[7] Zola P, Fuso L, Mazzola S, et al. Could follow-up different modalities play a role in asymptomatic cervical cancer relapses diagnosis? An Italian multicenter retrospective analysis. Gynecol Oncol 2007;107(1 Suppl 1):S150-4.

[8] Bandyopadhyay A, Mukherjee U, Ghosh S, et al. Pattern of failure with locally advanced cervical cancer - a retrospective audit and analysis of contributory factors. Asian Pac J Cancer Prev 2018;19(1):73-9.

[9] Rose PG, Java J, Whitney CW, et al. Nomograms predicting progression-free survival, overall survival, and pelvic recurrence in locally advanced cervical cancer developed from an analysis of identifiable prognostic factors in patients from NRG Oncology/Gynecologic Oncology group Randomized Trials of chemoradiotherapy. J Clin Oncol 2015;33(19):2136-42.
[10] Thigpen JT, Blessing JA, DiSaia PJ, et al. A randomized comparison of a rapid versus prolonged (24 hr) infusion of cisplatin in therapy of squamous cell carcinoma of the uterine cervix: a Gynecologic Oncology Group study. Gynecol Oncol 1989;32(2):198202.

[11] Neoadjuvant Chemotherapy for Cervical Cancer MetaAnalysis Collaboration (NACCCMA). Neoadjuvant chemotherapy for locally advanced cervix cancer. Cochrane Database Syst Rev 2004;(2):CD001774.

[12] Wang CC. Altered fractionation radiation therapy for gynecologic cancers. Cancer 1987;60(Suppl 8):2064-7.

[13] MacLeod C, Bernshaw D, Leung S, et al. Accelerated hyperfractionated radiotherapy for locally advanced cervix cancer. Int J Radiat Oncol Biol Phys 1999;44(3):519-24.

[14] Viswanathan FR, Varghese C, Peedicayil A, et al. Hyperfractionation in carcinoma of the cervix: tumour control and late bowel complications. Int J Radiat Oncol Biol Phys 1999;45(3):653-6.

[15] Grigsby PW, Heydon K, Mutch DG, et al. Long term follow-up of radiation therapy oncology group 92-10: cervical cancer with positive para-aortic lymph nodes. Int J Radiat Oncol Biol Phys 2001;51(4):982-7.

[16] Calkins AR, Harrison CR, Fowler WC Jr, et al. Hyperfractionated radiation therapy plus chemotherapy in locally advanced cervical cancer: results of two phase I dose-escalation gynecologic oncology group trials. Gynecol Oncol 1999;75(3):34955.

[17] Thomas G, Dembo A, Ackerman I, et al. A randomized trial of standard versus partially hyperfractionated radiation with or without concurrent 5-fluouracil in locally advanced cervical cancer. Gynecol Oncol 1998;69(2):137-45.

[18] Kavanagh BD, Gieschen HL, Schmidt-Ullrich RK, et al. A pilot study of concomitant boost accelerated superfractionated radiotherapy for stage III cancer of uterine cervix. Int J Radiat Oncol Biol Phys 1997;38(3):561-8.

[19] Muckaden MA, Budrukkar AN, Tongaonkar HB, et al. Hypofractionated radiotherapy in carcinoma cervix IIIB: Tata Memorial Hospital experience. Indian J Cancer 2002;39(4):127-34. 